\title{
Proceeding
}

Supplementary Issue: Spring Conferences of Sports Science. Costa Blanca Sports Science Events, 19-20 June 2020. Alicante, Spain.

\section{Physical activity and mental health in caregivers of mental ill patients in Greece}

\author{
THOMAS ZACHARIS1, GEORGIOS LYRAKOS ${ }^{2,3} 4$, VASILIKI Z. ZISI ${ }^{1}$ \\ ${ }^{1}$ Department of Physical Education and Sport Science, University of Thessaly, Trikala, Greece \\ ${ }^{2}$ City Unity College-Cardiff, United Kingdom \\ ${ }^{3}$ Department of Psychiatry, General Hospital Nikaia, Piraeus "Agios Panteleimon", Nikaia, Greece
}

\begin{abstract}
The present study is one of the first attempts to examine the connection of physical activity with the mental health of people that care for family members with mental illness. Caregiving is a load with negative effects on well-being but caring for a family member with mental illness results to a higher psychological burden, due to other factors involved (i.e. stigma). Physical activity and exercise have been found to be variables that lead to better quality of life for caregivers in many chronic illnesses. The participants of the study were 300 caregivers of patients with mental illness - family members (96 men, 204 women) of a mean age 60.64 $( \pm 10.08)$ years old. They were administered the Leisure Time Physical Activity questionnaire and according to their responses, they were divided in two groups: physically active and sedentary. Mental health was assessed using the DASS 21 questionnaire, with three subscales: depression, anxiety and stress. According to the results of the one-way MANOVA, physically active caregivers had a better score than their sedentary counterparts on all three DASS 21 subscales: anxiety $(p<.001)$, stress $(p<.01)$, depressive symptoms $(p<$ $.001)$. According to the results, physical activity and exercise of even low intensity, seems to play an important role on caregivers' mental health by leading to reduced stress, anxiety and depressive symptoms. Although more research is needed in this area, it seems that physical activity interventions should be considered as an additional type of support offered to caregivers of mental ill patients.
\end{abstract}

Keywords: Physical activity; Exercise; Mental health; Caregivers; Stress; Anxiety; Depression.

Cite this article as:

Zacharis, T., Lyrakos, G., \& Zisi, V.Z. (2020). Physical activity and mental health in caregivers of mental ill patients in Greece. Journal of Human Sport and Exercise, 15(3proc), S848-S855. doi:https://doi.org/10.14198/jhse.2020.15.Proc3.36

Corresponding author. Department of Physical Education and Sport Science, University of Thessaly, Trikala, Greece. https://orcid.org/0000-0001-9013-9863

E-mail: vzisi@pe.uth.gr

Supplementary Issue: Spring Conferences of Sports Science. Costa Blanca Sports Science Events, 19-20 June 2020. Alicante, Spain.

JOURNAL OF HUMAN SPORT \& EXERCISE ISSN 1988-5202

(c) Faculty of Education. University of Alicante

doi:10.14198/jhse.2020.15.Proc3.36

S848

| 2020 | Proc3 | VOLUME 15

(C) 2020 University of Alicante 


\section{INTRODUCTION}

Caregivers of patients with Schizophrenia have many responsibilities depending on the stage of the disease the patient is. Some of those responsibilities includes monitoring the patient's medication, accompanying the patient to the doctor, financial support for the patient, creating and maintaining the patient's daily routine, communicating with health professionals, and taking care of the symptoms of the disease as well as and the patient's hygiene. These responsibilities expose family caregivers to a heavy burden with negative consequences for them and the rest of the family (MacLeod et al., 2011). It was several years ago that Riley et al. (2011) pointed out that family caregivers of patients with schizophrenia experience significant difficulties in their everyday life. Knock et al. (2011) agreed that the burden on a family caregiver of a person with schizophrenia is very complex since the caregiver's daily routine is disrupted by his duties. Also, the social pressure exerted on family caregivers by people with severe mental disorders is quite high. Another study by Caqueo-Urizar et al. (2013) showed that the stress levels of family caregivers of patients with schizophrenia is increased due to difficulties in communication with the patients, lack of appropriate interventions and financial problems. It is of major importance to understand, that family caregivers of patients with mental disorders play the most important role in the everyday care of psychiatric patients and can prevent their incarceration in psychiatric institutions.

In another major disease (Bipolar disease), research has shown (Gurney, 2013; Perlik et al., 2008, 2007) that bipolar disorder affects a patient's family members and is affected by family's health-related environment. About $89 \%$ to $91 \%$ of family members report feelings of emotional distress about the severity of their symptoms. Also, more than $38 \%$ of those family caregivers are reporting the existence of depressive symptoms. In particular, patient's suicidal ideation and behaviour have been associated with increased symptoms of caregiver's depression.

On the other hand, researchers have linked physical activity with better mental health (Goodwin, 2003). They also point out that physical inactivity can lead to mental disorders. More specifically, there are evidence regarding a correlation between physical inactivity and poor mental health and physical inactivity with reduced stress and depression (Goodwin, 2003). Also, Sanderson and Taylor (1999) have reported that people involved in physical activity and sports tend to have better mental health. For example, they have lower levels of stress and less symptoms of anxiety and depression, regardless of gender, age and other demographic characteristics. Similarly, a research conducted in European Union countries by Abu-Omar et al. (2004), revealed a strong relation, between daily physical activities and good mental health in people who exercise regularly.

The important role of frequent physical activity in caregivers has been emphasized by Noghani et al. (2016). More specifically, the results of their study showed that caring for people with severe mental disorders causes a lot of psychological burden on family caregivers, leading to increased stress levels. Regular participation in physical activity played a crucial role in reducing caregivers' stress levels.

The present study aims to explore the connection between physical activity and mental health status in family caregivers of patients with mental illness. Caring for family members with mental illness results to a high psychological burden, since the caregiving is not the only stress factor, but there are also other factors involved, such as the social stigma. 


\section{MATERIAL AND METHODS}

\section{Participants}

The participants selected to participate in the study were 300 caregivers, family members, of patients with mental illness. Their mean age was $60.64( \pm 10.08)$ years old. A special effort was made to collect a representative number of caregivers from the Greek capital and the Greek province, thus $161(53,7 \%)$ of them were residents of Athens, while the rest were living in other cities of Greece. Participants' characteristics are depicted on Table 1.

Our study was conducted according to the Declaration of Helsinki and written consent was obtained from all participants before their participation in the study. The research protocol was fully approved by the Human Research Ethics Committee of the University of Thessaly, Greece, prior to the study. All participants were members of, and were conducted through, the Associations of Families for Mental Health from different cities of Greece like Korydallos, Patras, Maroussi, Byron, Thessaloniki, loannina, Viotia, Serres, Evros, Argolida, Keratsini-Drapetsonas, Kavala, Volos, Drama, Peristeri, Corfu and Paros.

Inclusion criteria was to be adult, to speak and write fluently the Greek language and to agree to complete the questionnaires. Caregivers with communication disorders and serious neurological or psychiatric illnesses were excluded from the study.

Table 1. Participants' characteristics in numbers and sample percentages (in parenthesis).

\begin{tabular}{|c|c|c|c|c|c|}
\hline \multicolumn{6}{|l|}{ Gender } \\
\hline Men & Women & & & & \\
\hline $96(32 \%)$ & $204(68 \%)$ & & & & \\
\hline \multicolumn{6}{|l|}{ Marital status } \\
\hline Single & Married & Divorced & Vacancy & Other & \\
\hline $36(12 \%)$ & $152(50.7 \%)$ & $43(14.3 \%)$ & $38(12.7 \%)$ & $31(10.3 \%)$ & \\
\hline \multicolumn{6}{|l|}{ Place of Residence } \\
\hline Attica & Province & & & & \\
\hline $161(53.7 \%)$ & $139(45.3 \%)$ & & & & \\
\hline \multicolumn{6}{|l|}{ Educational Level } \\
\hline $\begin{array}{c}\text { Primary School } \\
66(22 \%)\end{array}$ & $\begin{array}{c}\text { Grammar School } \\
60(20 \%)\end{array}$ & $\begin{array}{l}\text { High school } \\
100(33.3 \%)\end{array}$ & $\begin{array}{l}\text { University } \\
63(21 \%)\end{array}$ & $\begin{array}{l}\text { MSc-PhD } \\
11(3.7 \%)\end{array}$ & \\
\hline \multicolumn{6}{|l|}{ Profession } \\
\hline $\begin{array}{c}\text { State employee } \\
46(15.3 \%)\end{array}$ & $\begin{array}{c}\text { Private employee } \\
45(15 \%)\end{array}$ & $\begin{array}{l}\text { Freelance } \\
29(9.7 \%)\end{array}$ & $\begin{array}{c}\text { Home } \\
52(17.3 \%)\end{array}$ & $\begin{array}{c}\text { Unemployed } \\
39(13 \%)\end{array}$ & $\begin{array}{c}\text { Retired } \\
89(29.7 \%)\end{array}$ \\
\hline
\end{tabular}

\section{Design}

This study used a cross-sectional design to analyse the association between physical activity and mental health as it was measured through stress, anxiety and depression symptomatology in caregivers of mentally ill patients in Greece.

\section{Procedure}

Several Associations of Families for Mental Health around Greece were conducted in order to approach family caregivers, who were able and willing to participate in the study. Caregivers that were interested in participating in the study, were conducted by the researcher (the first author). The researcher summarized the purpose of the research, emphasizing that the participation was completely voluntary and the research 
data were completely confidential and available to any of the participants in the research process. The participants that signed informed consent for participation in the study, completed a questionnaire with their demographic characteristics. They received then the questionnaire forms and some instructions on how to complete them. The completion of the questionnaires required about 45 minutes and the participants had to return them in sealed envelopes, without any identification details except the serial number marked on the form.

\section{Measurements}

Mental health was assessed using the short version of the Depression, Anxiety, stress scale (DASS 21, Parkitny and McAuley, 2010). The questionnaire consists of 21 items in 4 point Likert scale ( $0=$ not at all valid for me, 3 = it was really valid for me/most of the times). It has three subscales: Anxiety Stress, and Depressive Symptomatology, of 7 items each. The higher the score, the more severe the symptoms. Internal consistency for each of the subscales of the questionnaire are reported to be high, both in the English version (.82 - .92), as well as in the Greek version (.90 -.94, Lyrakos et al., 2011).

Physical activity was estimated using the leisure time physical activity questionnaire (Godin and Shephard, 1985). According to the results in this questionnaire, participants were assigned in one of the physical activity groups: active, sedentary.

\section{Data analysis}

SPSS 24 (IBM SPSS Statistics 24.0, IBM SPSS® software, US) package program was used for the analysis of the data. The data presented normality according to the Shapiro-Wilk test. A one-way between groups multivariate analysis of variance (MANOVA) was performed to investigate group differences in Mental Health. The dependent variables were the three subscales of the DASS 21 questionnaire: Anxiety Stress, and Depressive Symptomatology. The independent variable was the physical activity group (active, sedentary). The alpha level of the separate univariate tests was set to .05.

\section{RESULTS}

Out of the 300 caregivers that agreed to participate in the study, 277 returned completed the questionnaire forms but only 266 of them were valid and were included in the statistical analysis.

\section{Physical activity}

According to the caregivers' answers in the Leisure time Physical Activity questionnaire, only 101 of them reported some physical activity, while the 165 were sedentary. As shown in Table 2, the majority of the active caregivers $(N=99)$ participated in low intensity activities in their spare time, while half of them $(n=51)$ reported participation also in physical activities of moderate intensity. A good number of active caregivers (n $=15$ ) mentioned participation in intense physical activity. Regular exercise was among the physical activity choices of the caregivers and some of the reported exercise features are presented on Table 2.

Table 2. Physical activity characteristics reported by the active caregivers.

\begin{tabular}{cccc}
\hline Physical activity intensity & Low & Moderate & Intense \\
\hline Number of participants & 99 & 51 & 15 \\
\hline Exercise features & Range & $\boldsymbol{M}$ & $\mathbf{S D}$ \\
\hline Exercise time/session (minutes) & $30-60$ & 46.48 & 33.92 \\
Exercise sessions per week & $1-7$ & 3.01 & 2.46 \\
Exercise years & $2-40$ & 10.96 & 7.72 \\
\hline
\end{tabular}




\section{Mental health}

The one-way MANOVA revealed a significant main effect of the group on the combined dependent variables, that is the three DASS 21 subscales (Wilks' Lamda $=.917, \mathrm{~F} 3,262=7.93, p<.001$, partial $\eta 2=.08$ ). When the results for the dependent variables were considered separately, all the differences were statistically significant at an alpha level of at least $p<.05$. As shown on Table 3 , physically active caregivers had a remarkably lower score on anxiety than the sedentary counterparts $(F 1,266=21.90, p<.001$, partial $\eta 2=$ .08). Sedentary caregivers reported also significantly higher stress levels $(F 1,266=8.26, p<.01$, partial $\eta 2$ $=.03)$ and depressive symptoms ( $F 1,266=5.48, p<.05$, partial $\eta 2=.02)$ than the physically active caregivers.

Table 3. Differences in mental health between physically active and sedentary caregivers.

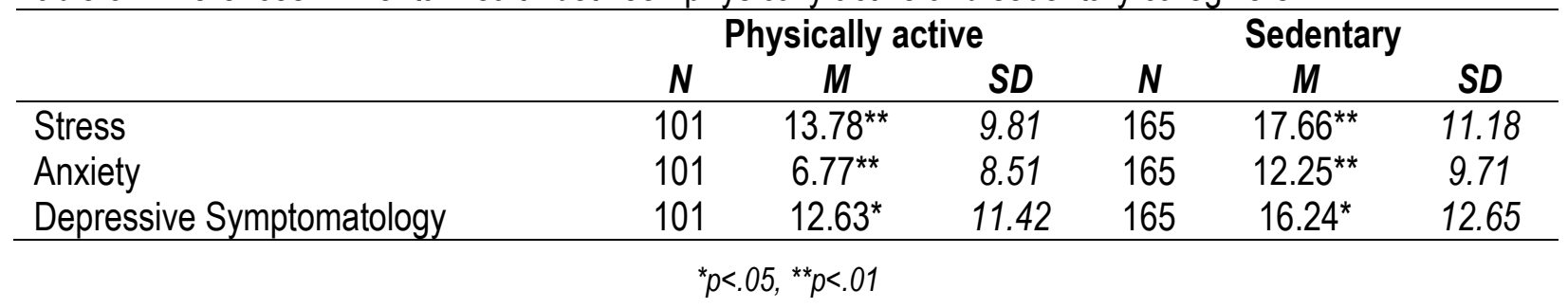

\section{DISCUSSION}

According to the findings of the present study, the majority of caregivers of patients with mental disorders were not physically active. Most of the physically active caregivers were participating in low intensity physical activity, since only half of them reported engagement in moderate activity and even fewer mentioned participation in intense physical activity. It seems that caring for family members is a quite heavy load in everyday life, which hinders physical activity. On the other hand, the findings of the present study suggest that physical activity, even of low intensity, seems to be important for caregivers' mental health.

Physically active caregivers seemed to benefit mainly on anxiety, which according to the DASS measures means lower physiological arousal, and avoidance of perceived panic and fear, while a lower score on the stress subscale is indicative of lower levels of tension and irritability (Parkitny and McAuley, 2010). These findings are in accordance with the findings of Puterman et al. (2018), who studied the effect of aerobic exercise on improving caregivers' mental health. According to the results of their study, 40 minutes of aerobic exercise, 3-4 times a week, may significantly improve the stress levels of caregivers, while improving also their mood.

The anxiolytic effect of exercise and especially aerobic exercise is well known, from long ago (Long and Stavel, 1995), an effect that was also confirmed for general physical activity (Strohle, 2009). Several studies tried to identify the type of exercise that is more beneficial for anxiety, for example as the study of Sharma, Madaan and Petty (2006), who concluded that aerobic exercise such as running, swimming, cycling, walking and dancing has been found to help reducing, not only anxiety but also depression. These types of exercise represents mainly physical activity of low and moderate intensity, and the results of the above study might be linked to the findings of the present study about the positive influence of physical activity on caregivers' depressive symptomatology.

The majority of the active caregivers in the present study reported participation in physical activity of low and moderate intensity, which was enough to lead to an improved score of DASS depression. The DASS measures of depressive symptoms are focusing on reports of low mood, as well as motivation and self- 
esteem (Parkitny and McAuley, 2010). These findings are in consistency with the findings of Ektin et al. (2008), who showed that physical activity improves the self-efficacy of family caregivers as it improves their well-being and helps them cope better with their daily tasks. It seems that there is a prolonged effect of exercise, beneficial for everyday activities. Indeed, according to Salmon (2001) and Ekkekakis and Petruzzello (1999), physical activity is able to directly reduce stress levels for a period of 2-4 hours after the end of the activity, which is observed regardless of gender and age.

The results of the present study and similar findings in the literature suggest that increased physical activity and exercise are important for caregivers' mental health and caring role. Exercise programs thus, should be considered as an additional type of support offered to caregivers of mental ill patients, but the exercise mental health relation in this population, is not clear yet. Research findings indicate that physical activity interventions may improve the stress, depression and burden in family caregivers, the small number of studies in this area however, is limiting the generalizability of these findings (Loi et al., 2014). Besides, participation in exercise programs and the beneficial exercise adherence depend on personal factors, such as motivation and intention to exercise. Findings suggest that mental health factors and attitudes about exercise may be more important predictors of exercise than the efficiency in the caregiving role (Etkin et al., 2008). Maybe a pleasant type of exercise or activities of a recreational type could be especially effective in easing the caregiving burden and improving mental health in caregivers of mentally ill patients, and research should shed more light in this area.

\section{CONCLUSSION}

The present study is one of the first attempts to examine the connection of physical activity with the mental health of family caregivers of mentally ill patients. Caregiving is a load with negative effects on well-being but caring for a family member with mental illness results to a higher psychological burden, due to other factors involved (i.e. stigma). Physical activity and exercise of even low intensity seems to play an important role on caregivers' mental health by leading to reduced stress, anxiety and depressive symptoms. Although more research is needed in this area, it seems that physical activity interventions should be considered as an additional type of support offered to caregivers of mental ill patients. Recreational activities, as a more pleasant type of physical activity, should be investigated as a mean of easing the caregiving burden and improving mental health in caregivers of mentally ill patients.

The research protocol was fully approved by the Human Research Ethics Committee of the University of Thessaly, Greece, prior to the study.

\section{AUTHOR CONTRIBUTIONS}

Conceptualization, T.Z. and V.Z.; Methodology and data analysis G.L.; writing—review \& editing, T.Z., G.L. and V.Z.

\section{SUPPORTING AGENCIES}

No funding agencies were reported by the authors.

\section{DISCLOSURE STATEMENT}

The authors declare no conflicts of interest. 


\section{REFERENCES}

Abu-Omar, K., Rütten, A. \& Robine, J. (2004). Self-rated health and physical activity in the European Union. Soz.-Präventivmed. 49, 235-242. https://doi.org/10.1007/s00038-004-3107-x

Caqueo Urízar, A., Miranda Castillo, C., Lemos Giraldez, S., Lee Maturana, S. L., Ramírez Pérez, M., \& Mascayano Tapia, F. (2014). An updated review on burden on caregivers of schizophrenia patients. Psicothema, 26 (2), 235-243.

Ekkekakis, P., \& Petruzzello, S. J. (1999). Acute aerobic exercise and affect. Sports Med., 28(5), 337347. https://doi.org/10.2165/00007256-199928050-00005

Etkin, C. D., Prohaska, T. R., Connell, C. M., Edelman, P., \& Hughes, S. L. (2008). Antecedents of physical activity among family caregivers. J Appl Gerontol, 27(3), 350-367. https://doi.org/10.1177/0733464808315276

Godin, G., \& Shephard, R. J., (1985). A simple method to assess exercise behavior in the community. Can J Appl Sport Sci, 10, 141-146.

Goodwin, R. D. (2003). Association between physical activity and mental disorders among adults in the United States. Prev Med, 36(6), 698-703. https://doi.org/10.1016/S0091-7435(03)00042-2

Gurney, S. (2013). The person with a bipolar affective disorder. The art and science of mental health nursing (3rd ed). Maidenhead: McGraw-Hill Education.

Knock, J., Kline, E., Schiffman, J., Maynard, A., \& Reeves, G. (2011). Burdens and difficulties experienced by caregivers of children and adolescents with schizophrenia-spectrum disorders: A qualitative study. Early Interv Psychia, 5(4), 349-354. https://doi.org/10.1111/j.17517893.2011.00305.x

Loi, S. M., Dow, B., Ames, D., Moore, K., Hill, K., Russell, M., \& Lautenschlager, N. (2014). Physical activity in caregivers: What are the psychological benefits?. Arch Gerontol Geriat, 59(2), 204-210. https://doi.org/10.1016/i.archger.2014.04.001

Long, B. C., \& Stavel, R. V. (1995). Effects of exercise training on anxiety: A meta- analysis. J Appl Sport Psychol, 7(2), 167-189. https://doi.org/10.1080/10413209508406963

Lyrakos, G. N., Arvaniti, C., Smyrnioti, M., \& Kostopanagiotou, G. (2011). Translation and validation study of the Depression Anxiety Stress Scale in the Greek general population and in a psychiatric patient's sample. Eur Psychiat, 26(S2), 1731. https://doi.org/10.1016/S0924-9338(11)73435-6

Macleod, S.H., Elliott, L., \& Brown, R. (2011). What support can community mental health nurses deliver to carers of people diagnosed with schizophrenia? Findings from a review of the literature. Int J Nurs Stud, 48(1), 100-120. https://doi.org/10.1016/i.jinurstu.2010.09.005

Noghani, F., Seyedfatemi, N., Karimirad, M. R., Akbarzadeh, A., \& Hasanpour-Dehkordi, A. (2016). Health related quality of life in family caregivers of patients suffering from mental disorders. J Clin Diagn Res: JCDR, 10(11), VC05-VC09. https://dx.doi.org/10.7860/JCDR/2016/19671.8792

Parkitny, L., \& McAuley, J. (2010). The depression anxiety stress scale (DASS). J Physiother, 56 (3), 204. https://doi.org/10.1016/S1836-9553(10)70030-8

Perlick, D. A., Rosenheck, R. A., Miklowitz, D. J., Chessick, C., Wolff, N., Kaczynski, R., ... \& STEP-BD Family Experience Collaborative Study Group. (2007). Prevalence and correlates of burden among caregivers of patients with bipolar disorder enrolled in the Systematic Treatment Enhancement Program for Bipolar Disorder. Bipolar Disord, 9(3), 262-273. https://doi.org/10.1111/j.13995618.2007.00365.x

Perlick, D. A., Rosenheck, R. A., Miklowitz, D. J., Kaczynski, R., Link, B., Ketter, T., ... \& STEP-BD Family Experience Collaborative Study Group. (2008). Caregiver burden and health in bipolar disorder: a cluster analytic approach. J Ner Ment Dis, 196(6), 484-491. https://doi.org/10.1097/NMD.0b013e3181773927 
Puterman, E., Weiss, J., Lin, J., Schilf, S., Slusher, A. L., Johansen, K. L., \& Epel, E. S. (2018). Aerobic exercise lengthens telomeres and reduces stress in family caregivers: A randomized controlled trialCurt Richter Award Paper 2018 Psychoneuroendocrinology, 98, 245-252. https://doi.org/10.1016/j.psyneuen.2018.08.002

Salmon, P. (2001). Effects of physical exercise on anxiety, depression, and sensitivity to stress: a unifying theory. Clin Psychol Rev, 21(1), 33-61. https://doi.org/10.1016/S0272-7358(99)00032-X

Sanderson, B. K., \& Taylor Jr, H. A. (1999). Physical activity. In Handbook of Health Promotion and Disease Prevention (pp. 191-206). Springer. https://doi.org/10.1007/978-1-4615-4789-1_10

Sharma, A., Madaan, V., \& Petty, F. D. (2006). Exercise for mental health. Prim Care Companion J Clin Psychiatry, 8(2), 106.

Ströhle, A. (2009). Physical activity, exercise, depression and anxiety disorders. J Neural Transm, 116(6), 777-784. https://doi.org/10.1007/s00702-008-0092-x 